\title{
CORRELATION BETWEEN SERUM hS-CRP AND LDL CHOLESTEROL AS A PREDICTOR OF CARDIOVASCULAR DISEASES
}

\author{
Md. Ezaz Zafar', Md. Faizur Rahman²
}

${ }_{1}^{1}$ Associate Professor, Department of Biochemistry, Katihar Medical College, Katihar.

${ }^{2}$ Associate Professor, Department of Biochemistry, Katihar Medical College, Katihar.

\section{ABSTRACT}

\section{BACKGROUND}

Of novel risk factors for cardiovascular disease currently under investigation, High-Sensitivity C-Reactive Protein (hs-CRP) is the most promising. Circulating levels of C-Reactive Protein (CRP) may constitute an independent risk factor for cardiovascular disease. How CRP as a risk factor is involved in cardiovascular disease is still to be discovered. In order to determine the better diagnostic marker and their probable role in the pathogenesis of IHD in comparison to serum LDL-C, we evaluated hsCRP.

\section{METHODS}

For this study, 90 patients of myocardial infarction and 90 controls irrespective of age and sex were studied for these parameters over a period of 1 year. Lipid profile and hs-CRP was estimated by using commercial kit on autoanalyzer and Elisa reader.

\section{RESULT}

The statistical analysis showed that the serum hsCRP was significantly raised in myocardial infarction cases than controls $(\mathrm{p}<0.005)$, but LDL-C was not $(\mathrm{p}>0.019)$.

\section{CONCLUSION}

On the basis of present study, it may be concluded that the serum hsCRP contribute as an independent risk factor for atherosclerosis and other CVD.

\section{KEYWORDS}

Myocardial Infarction, Atherosclerosis, hsCRP, LDL-C, CVD.

HOW TO CITE THIS ARTICLE: Zafar ME, Rahman MF. Correlation between serum hs-CRP and LDL cholesterol as a predictor of cardiovascular diseases. J. Evolution Med. Dent. Sci. 2016;5(32):1725-1728, DOI: 10.14260/jemds/2016/407

\section{INTRODUCTION}

Cardiovascular Diseases (CVDs) are the biggest cause of death worldwide. Over the past two decades, deaths from CVDs have been declining in high-income countries, but have increased at an astonishingly fast rate in Low- and Middle-Income Countries (LMIC). CVDs are largely preventable. Both, population wide measures and improved access to individual health care interventions can result in a major reduction in the health and socioeconomic burden caused by these diseases and their risk factors.(1) For more than 30 years blood pressure, smoking status, hyperlipidaemia and the presence or absence of diabetes was considered as cardiovascular risk factor. These core traditional risk factors for heart disease and stroke derive largely from the ground breaking Framingham Heart Study that first provided the conceptual basis for cardiovascular risk factors in the early 1960s.(2) Due to extensive research and identification of the aetiopathogenic basis of Cardiovascular Disease (CVD) as well as the diverse mechanisms implicated in the onset and progression of atherosclerosis, current studies in this area focus in the characterization of biomarkers for the early detection of the inflammatory activation underlying this process.

Financial or Other, Competing Interest: None.

Submission 04-03-2016, Peer Review 31-03-2016,

Acceptance 05-04-2016, Published 21-04-2016.

Corresponding Author:

Dr. Md. Ezaz Zafar,

Associate Professor,

Department of Biochemistry,

Katihar Medical College,

Katihar.

E-mail: ezazzafar@yahoo.co.in

DOI: $10.14260 /$ jemds/2016/407
The atherosclerosis is major cause of IHD and other CVDs. It is a chronic inflammatory response of the arterial wall initiated by injury to the endothelium. Moreover, lesion progression is sustained by interaction between modified lipoproteins (eg. oxidized LDL), monocyte-derived macrophage (Foam cells), T-lymphocytes and the normal cellular constituents of the arterial wall. Atherosclerosis is characterized by thickening of the arterial wall, which protrudes into and obstructs the vascular lumen.(3) The biomolecule with the greater body of research both from a molecular and epidemiological perspective is C-Reactive Protein (CRP), a plasma protein of the pentraxin family and an acute phase reactant, which displays high sensitivity as a general inflammation marker.(4) Numerous studies have demonstrated the active participation of this molecule in the atherogenic process. ${ }^{(5)}$ and due to the discovery of highsensitivity techniques for its determination, its stable plasmatic concentrations and its relatively low costs, it may be of great use in the identification of patients at high risk as a prognostic indicator and even as a therapeutic target in large populations.

More than 20 prospective epidemiologic studies have demonstrated that hs-CRP independently predicts vascular risk, 6 cohort studies have confirmed that hs-CRP evaluation adds prognostic information beyond that available from the Framingham Risk Score and 8 cohort studies have demonstrated additive prognostic value at all levels of metabolic syndrome or in the prediction of type 2 diabetes. Low Density Lipoprotein (LDL), which is called bad cholesterol, rich in cholesterol ester, participates in the atherosclerotic process. Dyslipidaemia with particular reference to LDL cholesterol has also been considered as risk factor for development of atherosclerosis.(6) 
Although, there are plenty of studies which confirmed the hs-CRP as predictor of CVD, but its comparative importance with LDL-C is still a far cry. The present study is an attempt to establish a correlation between serum LDL-C and hs-CRP, which has greater importance.

\section{MATERIAL AND METHODS}

This study was conducted in the Biochemistry Department of Katihar Medical College and Hospital. Ninety patients irrespective of age and sex diagnosed as myocardial infarction clinically as well as by ECG and cardiac markers were chosen as cases. The controls were selected from the persons, neither suffering from any type of cardiovascular disease nor taking any drug from same region. Both the cases and controls were selected by a simple random method. After noting the name, age and sex, venous samples were drawn after 12 hours of overnight fasting. Serum was separated and assays were performed within 24 hours. Serum hs-CRP was measured by sandwich Enzyme Linked Immunosorbent Assay (ELISA). ${ }^{(7)}$ Serum total cholesterol, Triglyceride (TG) and High Density Lipoprotein (HDL) were assayed by Cholesterol OxidasePeroxidase (CHOD-PAP), Glycerol-3-Phosphate Oxidase (GPO) and polyanion precipitation methods respectively using semiautoanalyzer. Serum Very Low Density Lipoprotein (VLDL) was calculated by dividing the value of TG by 5 and serum LDL was obtained by Friedewald equation.(8) The value of hsCRP $>3 \mathrm{mg} / \mathrm{L}$ (9) was considered as high risk for cardiovascular diseases. The data for biochemical analysis was subjected to standard statistical analysis such as student ' $\mathrm{t}$ ' test using the Statistical Package for Social Science (SPSS) 11.5 software.

\section{RESULTS AND DISCUSSION}

Results are given in the tables. In cases, the mean value of hsCRP was found to be $3.7222 \pm 0.62401$ and in control $0.5778 \pm 0.16517(\mathrm{p}<0.005)$ Table 1 . The mean value of LDL-C among cases and control were estimated as $97.34 \pm 18.60057$ and $89.33 \pm 9.00312$ respectively ( $p>0.019$ ). The increase level of hs-CRP was highly significant as compared to their normal counterpart. Although, the level of LDL-C among the cases was significantly increased as compared to their control, but the level was not highly elevated.

\begin{tabular}{|c|c|}
\hline & $\begin{array}{c}\text { Concentration of hsCRP (mg/L) } \\
\text { (Mean } \pm \text { SD) }\end{array}$ \\
\hline IHD Cases & $3.7222 \pm 0.62401$ \\
Control & $0.5778 \pm 0.16517$ \\
\hline P value & 0.005 \\
\hline Table 1: Comparison of Mean of hs-CRP between the \\
cases Suffering from Myocardial Infarction and \\
Controls \\
\hline
\end{tabular}

\begin{tabular}{|c|c|}
\hline & $\begin{array}{c}\text { Concentration of LDL-C (mg/dL) } \\
\text { (Mean } \pm \text { SD) }\end{array}$ \\
\hline IHD Cases & $97.34 \pm 18.60057$ \\
Control & $89.33 \pm 9.00312$ \\
\hline p value & 0.019 \\
\hline Table 2: Comparison of Mean of LDL-C between the \\
cases Suffering from Myocardial Infarction and \\
Controls
\end{tabular}

These results suggest that serum hsCRP level was significantly higher in cases of myocardial infarction. Inflammation has a key role in the pathophysiology of atherosclerosis.(10,11) Macrophages present in the atherogenous plaque lead to release of additional mediators like cytokines and chemokines, which in turn increase the plasma concentration of CRP which amplify inflammatory and procoagulant responses.(12) Therefore, markers of inflammation such as CRP have been investigated for risk estimation of cardiovascular event. However, in atherosclerosis, low-grade inflammation has been recognized, so CRP concentration are often lower than measuring range of traditional CRP assay. Due to this for suspected cardiac cases hs-CRP (High Sensitivity CRP) was measured. Many assay techniques for hs-CRP measurement are now commercially available, which give accurate and reproducible results.

JUPITER study.(13) demonstrate the usefulness of CRP for the identification of subjects in risk and they also hint towards its potential role as a therapeutic target in the atherosclerotic process.(14) In this aspect, hs-CRP is more than a simple biomarker and current findings tightly link this protein with the CVD. Its implementation is based on the guidelines suggested by the NACB, which delimit its application to a certain population at risk and sets a cut-off point for its serum levels. However, many aspects still remain to be elucidated, requiring the assessment of CRP behaviour across ethnic groups (Asians, Africans and Hispanics) since most studies have been limited to European and North American cohorts. Likewise, further research would clarify the true role of CRP in the development of CVD.(15) Furthermore, research is being expanded to further age groups, analyse the impact of hs-CRP in coronary event prognosis and decipher the phenomena linking it to the atherogenic process in order to exploit its potential efficacy as a therapeutic target.(16,17) The answers to these matters would allow the confirmation of the feasibility of hs-CRP quantification and the formulation of management guidelines for our patients, based on the measurement and the clinical picture of each individual.

Because of its clinical importance in atherogenesis, LDL is the focus of current guidelines for the determination of the risk of cardiovascular disease. It is noteworthy that only half of all patients with coronary heart disease have any one of the established risk factors like-hypertension, hypercholesterolemia, cigarette smoking, diabetes mellitus, marked obesity and physical inactivity. Braunwald in his scholarly lecture has listed some emerging cardiovascular risk factors, C-reactive proteins being one of them.(18) It has been shown that maximum myocardial infarction cases have serum hsCRP level more than $3 \mathrm{mg} / \mathrm{L}$, though they have normal serum LDL level. After extensive data analysis, Willerson inferred that high CRP/Low LDL-C persons are at higher absolute risk than low CRP/high LDL-C persons.(19)

European Society of Cardiology guidelines for the prevention of heart disease strongly endorse cholesterol screening. Those same guidelines are silent on C-reactive protein.(20) Inflammation is a fundamental component of atherosclerosis.(21) For more than a decade, data from largescale prospective cohorts in the USA and Europe have consistently indicated that the predictive value of the inflammatory biomarker C-reactive protein is at least as large as that of cholesterol.(22,23) This observation is important since half of all heart attacks and strokes occur among those with 
average if not low cholesterol levels. That C-reactive protein and lipids are equal contributors to vascular risk has recently been confirmed in an elegant 2012 meta-analysis published in the New England Journal of Medicine by the Emerging Risk Factors Collaboration that analysed data from 38 prospective studies and included 166596 men and women without prior disease.(24) In 2008, in a fully parallel manner the JUPITER trial answered this crucial question in primary prevention for those who had elevated levels of C-reactive protein, but who otherwise would not qualify for statin therapy as they already had levels of LDL-C below treatment thresholds. (25)

In brief, among 17802 individuals with LDL-C 3.36 mmol/L (Median $1 / 42.7 \mathrm{mmol} / \mathrm{L}$ ), but who were identified at increased vascular risk due to $\mathrm{C}$-reactive protein levels $>2$ $\mathrm{mg} / \mathrm{L}$ (Median $4.1 \mathrm{mg} / \mathrm{L}$ ), rosuvastatin reduced major vascular events by $44 \%$ (P 0.0001$)$ and all-cause mortality by $20 \%\left(\mathrm{P}^{1 / 4}\right.$ 0.02). JUPITER also extended the statin literature in primary prevention to include women and non-Caucasian participants, all of whom experienced similar risk reductions. While there was no relationship in JUPITER between baseline LDL-C and subsequent benefit (An observation consistent with many studies in secondary prevention), those with sequentially higher baseline C-reactive protein values in JUPITER had higher absolute risk. (26-28)

Therefore, it can be suggested that the serum hs-CRP level is a strong predictor of cardiovascular events than the serum LDL-C. Therefore, future research should continue to more thoroughly study the effects of the reduction of serum hs-CRP levels. The designation of new risk factors stemming from advances in the comprehension of the inflammatory physiopathology of CVD has led research to try and elucidate which of these novel and emergent elements display all required criteria to be considered true risk factors and which have solely exhibited a casual statistical association. High sensitivity C-reactive protein is one of the numerous molecules that fit this description, but its properties and features have led it to become one of the main targets for researchers worldwide.

\section{ACKNOWLEDGEMENT}

I acknowledge the support and permission of KMCH authority for this study. I also acknowledge the people who unhesitatingly cooperated in this study.

\section{REFERENCES}

1. World Health Organization. Global status report on noncommunicable diseases. Geneva, WHO, 2010.

2. Kannel WB, Dawber TR, Kagan A, et al. Factors of risk in development of coronary heart disease: six year followup experience. The framingham study. Ann Intern Med 1961;55:33-50.

3. Vinay Kumar, Abul K Abbas, Nelson Fausto. Robbins and Cotran pathologic basis of disease, $7^{\text {th }}$ Edition. Philadelphia: Saunder WB Company, 2007;pp 516.

4. Pepys MB, Hirschfield GM. C-reactive protein: a critical update. Journal of Clinical Investigation 2003;111(12):1805-12.

5. Bisoendial RJ, Boekholdt SM, Vergeer M, et al. C-reactive protein is a mediator of cardiovascular disease. European Heart Journal 2010;31(17):2087-95.
6. Expert Panel on Detection, Evaluation and treatment of High Blood Cholesterol in Adults. Executive summary of the third report of the national cholesterol education program (NCEP) expert panel on detection, evaluation, and treatment of high blood cholesterol in adults (Adult Treatment Panel III). JAMA 2001;285(19):2486-97.

7. Uotila M, Ruoslanti E, Enguall E. Two-site sandwich enzyme immunoassay with monoclonal antibodies to human alpha-fetoprotein. Immunol methods 1981;42(1):11-5.

8. Pearson TA, Mensah GA, Alexander RW, et al. Markers of inflammation and cardiovascular diseases. Application to clinical and public health practice: a statement for health care professionals from the center for disease control and prevention and the American heart association. Circulation 2003;107:499-511.

9. Carl A Burtis, Edward R Ashwood. Tietz text book of clinical chemistry. Singapore: Saunder WB Company, 1999;3 $3^{\text {rd }}$ edn:pp 843.

10. Ridker PM. The pathogenesis of atherosclerosis and acute thrombosis relevance to strategies of cardiovascular disease prevention. In prevention of myocardial infarction. Manson JE, Ridker PM, Gaziano JM, et al. Eds. New York, Oxford University Press, 1996;p 32-54.

11. Ridker PM. Inflammation, infection and cardiovascular risk: how good is the clinical evidence? Circulation 1998;97(17):1671-4.

12. Pasceri V, Willerson JT, Yeh ET. Direct proinflammatory effect of C-freactive protein on human endothelial cells. Ciuculation 2000;102(18):2165-8.

13. Braunwald E. Sahttuck lecture-cardiovascular medicine at the turn of the millennium: triumph, concerns and opportunities. N Engl J Med 1997;337:1360-9.

14. Willerson JT, Ridker PM. Inflammation as a cardiovascular risk factor. Circulation 2004;109:II2-II10.

15. Oh J, Teoh H, Leiter LA. Should C-reactive protein be a target of therapy? Diabetes Care 2011;34(2):S155-60.

16. Berm'udez V, Rojas E, Salazar JJ, et al. Coronary risk estimation according to the framingham-wilson score: epidemiologic behavior of innovative cardio metabolic risk factors in the maracaibo city. International Journal of Cardiovascular Research 2013; Vol 2:Article 4.

17. Ong KL, Allison MA, Cheung BM, et al. Trends in C-reactive protein levels in US adults From 1999 to 2010. American Journal of Epidemiology 2013;177(12):1430-42.

18. Berm'udez V, Cabrera M, Mendoza L, et al. High-sensitivity C-reactive protein epidemiological behavior in adult individuals from maracaibo, venezuela. Revista Latinoamericana de Hipertension 2013;8(1):22-9.

19. Perk J, De Backer G, Gohlke H, et al. European guidelines on cardiovascular disease prevention in clinical practice (Version 2012). Fifth joint task force of the european society of cardiology and other societies on cardiovascular disease prevention in clinical practice. Eur Heart J 2012;33(13):1635-701.

20. Libby P, Ridker PM, Hansson GK. Inflammation in atherosclerosis: from pathophysiology to practice. J Am Coll Cardiol 2009;54(23):2129-38.

21. Ridker PM, Rifai N, Rose L, et al. Comparison of C-reactive protein and low-density lipoprotein cholesterol levels in the prediction of first cardiovascular events. N Engl J Med 2002;347(20):1557-65. 
22. Koenig W, Lowel H, Baumert J, et al. C-reactive protein modulates risk prediction based on the framingham score: implications for future risk assessment: results from a large cohort study in southern Germany. Circulation 2004;109(11):1349-53.

23. The Emerging Risk Factors Collaboration. C-reactive protein, fibrinogen, and cardiovascular disease prediction. N Engl J Med 2012;367:1310-20.

24. Ridker PM, Danielson E, Fonseca FA, et al. Rosuvastatin to prevent vascular events in men and women with elevated C-reactive protein. N Engl J Med 2008;359:2195-207.

25. Ridker PM, MacFadyen J, Libby $P$, et al. Relation of baseline high-sensitivity C-reactive protein level to cardiovascular outcomes with rosuvastatin in the justification for use of statins in prevention: an intervention trial evaluating rosuvastatin (JUPITER). Am J Cardiol 2010;106(2):204-9.
26. Hingorani AD, Sofat R, Morris RW, et al. Is it important to measure or reduce $\mathrm{C}$-reactive protein in people at risk of cardiovascular disease? Eur Heart J 2012;33(18):225864.

27. Shepherd J, Cobbe SM, Ford I, et al. Prevention of coronary heart disease with pravastatin in men with hypercholesterolemia. West of scotland coronary prevention study group. N Engl J Med 1995;333:1301-8.

28. Ridker PM, Danielson E, Fonseca FA, et al. Reduction in creactive protein and LDL cholesterol and cardiovascular event rates after initiation of rosuvastatin: a prospective study of the JUPITER trial. The Lancet 2009;373(9670):1175-82. 